University of Wollongong

Research Online

Faculty of Social Sciences - Papers (Archive) Faculty of Arts, Social Sciences \& Humanities

$1-1-2016$

Biopedagogies and Indigenous knowledge: examining sport for development and peace for urban Indigenous young women in Canada and Australia

Lyndsay M C Hayhurst

Brock University

Audrey R. Giles

University of Ottawa

Jan Wright

University of Wollongong, jwright@uow.edu.au

Follow this and additional works at: https://ro.uow.edu.au/sspapers

Part of the Education Commons, and the Social and Behavioral Sciences Commons

Research Online is the open access institutional repository for the University of Wollongong. For further information contact the UOW Library: research-pubs@uow.edu.au 


\title{
Biopedagogies and Indigenous knowledge: examining sport for development and peace for urban Indigenous young women in Canada and Australia
}

\begin{abstract}
This paper uses transnational postcolonial feminist participatory action research (TPFPAR) to examine two sport for development and peace (SDP) initiatives that focus on Indigenous young women residing in urban areas, one in Vancouver, Canada, and one in Perth, Australia. We examine how SDP programs that target urban Indigenous young women and girls reproduce the hegemony of neoliberalism by deploying biopedagogies of neoliberalism to 'teach' Indigenous young women certain education and employment skills that are deemed necessary to participate in competitive capitalism. We found that activities in both programs were designed to equip the Indigenous girls and young women with individual attributes that would enhance their chances of future success in arenas valued by neoliberal capitalism: Eurocentric employment, post-secondary education and healthy active living. These forms of 'success' fall within neoliberal logic, where the focus is on the individual being able to provide for oneself. However, the girls and young women we interviewed argued that their participation in the SDP programs would help them change racist and sexist stereotypes about their communities and thereby challenged negative stereotypes. Thus, it is possible that these programs, despite their predominant use of neoliberal logic and biopedagogies, may help to prepare the participants to more successfully negotiate Eurocentric institutions, and through this assist them participants in contributing to social change. Nevertheless, based on our findings, we argue that SDP programs led by Indigenous peoples that are fundamentally shaped by Indigenous voices, epistemologies, concerns and standpoints would provide better opportunities to shake SDP's current biopedagogical foundation. We conclude by suggesting that a more radical approach to SDP, one that fosters Indigenous self-determination and attempts to disrupt dominant relations of power, could have difficulty in attracting the sort of corporate donors who currently play such important roles in the current SDP landscape.
\end{abstract}

\section{Keywords}

young, biopedagogies, urban, peace, development, sport, examining, knowledge, australia, canada, women, indigenous

\section{Disciplines}

Education | Social and Behavioral Sciences

\section{Publication Details}

Hayhurst, L. M C., Giles, A. R. \& Wright, J. (2016). Biopedagogies and Indigenous knowledge: examining sport for development and peace for urban Indigenous young women in Canada and Australia. Sport, Education and Society, 21 (4), 549-569. 
Hayhurst, Giles \& Wright (2016) Biopedagogies and Indigenous Knowledge: Examining sport, gender and development (SGD) for Indigenous urban young women in Canada and Australia, Sport Education and Society, doi: 10.1080/13573322.2015.1110132

\begin{abstract}
This paper uses transnational postcolonial feminist participatory action research (TPFPAR) to examine two sport for development and peace (SDP) initiatives that focus on Indigenous young women residing in urban areas, one in Vancouver, Canada, and one in Perth, Australia. We examine how SDP programs that target urban Indigenous young women and girls reproduce the hegemony of neo-liberalism by deploying biopedagogies of neo-liberalism to ‘teach' Indigenous young women certain education and employment skills that are deemed necessary to participate in competitive capitalism. We found that activities in both programs were designed to equip the Indigenous girls and young women with individual attributes that would enhance their chances of future success in arenas valued by neoliberal capitalism: Eurocentric employment, post-secondary education, and healthy active living. These forms of 'success' fall within neoliberal logic, where the focus is on the individual being able to provide for oneself. However, the girls and young women we interviewed argued that their participation in the SDP programs would help them change racist and sexist stereotypes about their communities and thereby challenged negative stereotypes. Thus, it is possible that these programs, despite their predominant use of neoliberal logic and biopedagogies, may help to prepare the participants to more successfully negotiate Eurocentric institutions, and through this assist them participants in contributing to social change. Nevertheless, based on our findings, we argue that SDP programs led by Indigenous peoples that are fundamentally shaped by Indigenous voices, epistemologies, concerns and standpoints would provide better opportunities to shake SDP's current biopedagogical foundation. We conclude by suggesting that a more radical approach to SDP, one that fosters Indigenous self-determination and attempts to disrupt dominant relations of power, could have difficulty in attracting the sort of corporate donors who currently play such important roles in the current SDP landscape.
\end{abstract}

Keywords: Indigenous pedagogy, sport for development, young women, Canada, Australia, biopedagogies, neoliberalism, corporatization 


\section{Introduction}

We write this paper at a critical moment in history. The recent release of the Truth and Reconciliation Commission report, detailing the cultural genocide experienced by Indigenous peoples in Canada, has forcefully impelled Canadians to realize how they are implicated in the current social, economic and political conditions in which many Indigenous peoples live (Truth and Reconciliation Commission of Canada, 2015). With intensifying debate about the best strategies for rectifying the effects of the residential school system and human-rights abuses involving Indigenous peoples in Canada, and in other settler colonial countries such as Australia, non-governmental organizations, non-for-profit entities and corporations are increasingly using social development and employment programs in their attempts to address these issues - and at the same time secure their own interests - through various initiatives focused on sport.

Sport for development and peace (SDP) interventions have been used in recent years for a variety of purposes, including addressing conflict resolution, gender inequalities, and communicable diseases in communities across the global North and South (Wilson, B. 2012). Though SDP is a relatively new term - and arguably a 'new' social movement (see Kidd, 2008) - sport has long been used as a tool to promote the 'development' and 'education' of Indigenous communities and their residents in Canada and Australia (see Giles, 2009; Rossi \& Rynne, 2014). For example, there is a long and appalling history of its use as part of the residential school system in Canada as a 'civilizing' and ‘colonizing’ tool (Hayhurst \& Giles, 2013; Hayhurst et al., 2015). 
Despite the widely held assumption that SDP inherently utilizes educational strategies, few studies have teased apart SDP and its distinct (bio)pedagogical tactics (exceptions include Forde \& Frisby, 2015) - that is, how sport, as it is enmeshed with development, is used as a site and a vehicle to engage the 'capacities' of those targeted to 'gain knowledge, skills and resources to constitute their identities' (Author 3, 2014). More specifically, we contend that there is a potentially novel tenet of the SDP terrain that has been largely unaccounted for: the utility of sport as it functions as a biopedagogical apparatus through which norms and ideologies related to Eurocentrism, citizenship, neoliberalism, employability, self-reliance, and 'healthy living and bodies' are disseminated and perpetuated (cf., Author 3, 2014).

In the pages that follow, we consider these contentions further by examining SDP programs that focus on Indigenous young women in Canada and Australia residing in urban communities. Specifically, we examine how SDP programs that target urban Indigenous young women in Vancouver, Canada and Perth, Australia reproduce the hegemony of neoliberalism by deploying the biopedagogies of neoliberalism to ‘teach’ Indigenous young women the 'healthy living' and employment skills that are deemed necessary to participate in competitive capitalism.

In the discussion section of the paper, however, we argue that this need not be the case, that SDP programs have the potential to be used in ways that can promote Indigenous peoples’ selfdetermined goals and values. We note that the organizations examine here do, to an extent, engage with these goals and values in various ways, but that there are more opportunities to ensure that SDP is better informed by Indigenous knowledge and pedagogies (Grande, 2008; Kincheloe \& Steinberg, 2008) in order to take better account of the Indigenous identities of the young people they target.

To argue this position, we draw on the concepts of biopedagogies (Author 3, 2009), neoliberalism (Harvey, 2005) and Indigenous pedagogies and knowledge (Kincheloe \& Steinberg, 
2008) to better understand the key tensions underlying the logic of SDP interventions that aim to 'teach’ Indigenous young women in Canada and Australia how to become apparently healthier, employable and successful citizens. Our study is guided by two key research questions: 1) Can urban young Indigenous women in Canada and Australia engage with the grammar of biopedagogies of neoliberalism deployed vis-à-vis SDP programs without replicating its effects; and 2) how might SDP programs that focus on Indigenous peoples be informed by Indigenous knowledges and pedagogies?

\section{Sport for Development and Peace, NGO-corporate partnerships and neoliberalism}

For the purposes of this paper, neoliberalism is understood as a political and economic ideology, and praxis, that is characterized by market-based governance practices, privatization, commodification, efficiency, individualism, competition and the dismantling of the welfare state (Harvey, 2005). Mohanty (2013) further argues that from a feminist, postcolonial perspective, neoliberalism normalizes market democracies, privatizes notions of agency and difference and depoliticizes racialized, classed and gendered hierarchies. In short, global neoliberalism is incompatible with solidarity-focused, collective forms of social justice - the very essence of what SDP (cl)aims to represent (cf., Hayhurst 2011).

In recent years, the neoliberal tendencies and character of the SDP movement have been welldocumented by scholars such as Darnell (2012), who has suggested that SDP programs provide opportunities through which to further understand the hegemony of neoliberalism in and through sport - including the neoliberal rationales, such as racialization and 'managing the conduct of others' to ensure they are responsible for their own health and well-being, that often align with sport and international development work. These studies document how inequalities in SDP - exacerbated 
through neoliberalism - are experienced, contested, maintained and/or reproduced (e.g., Hayhurst \& Giles, 2013; Lindsey \& Grattan, 2012).

Indeed, much of this influential literature been informed by a vast collection of research that examines neoliberal understandings of sport 'as an economy of affect through which power, privilege and politics are (re)produced' (Andrews \& Silk, 2012, p. 5). Such understandings of sport are crucial to connect SDP with broader discussions of neoliberalism and its effects, particularly in terms of the ways in which practices of neoliberalism relate to the privatization of SDP, and the increasing blurring of boundaries between corporations, NGOs and the state. This scholarly focus mimics recent research in other sectors, particularly in physical education (in a recent Special Issue of this journal, see Evans \& Davies, 2014) and global education more broadly (e.g., Bhanji, 2008). For example, Powell (2014, p. 233) contends that partnerships among NGOs, school boards and corporations result in 'corporate curricula', and suggests that, through this ‘corporate curricula', children and youth are taught to be more responsible for their own health, and other more complex determinants of health (e.g., poverty, colonialism) are ignored. Though we have critically interrogated the implications of the privatization of SDP interventions for Indigenous communities in Canada and Australia through corporate-NGO partnerships (see Hayhurst, Giles \& Wright, 2015), the effects of these partnerships have not been examined pedagogically, particularly from the perspectives of Indigenous young women and NGO staff.

\section{Biopedagogies: Learning Citizenship, Healthy Living and Self-Responsibility through SDP?}

Harwood (2009, p. 15) argues that common across a range of contexts are instructions on how to live: 'how to live, how to eat, how much to eat, how to move, how much to move'. Author 3 (2009) uses the 
term biopedagogies to capture these normalizing and regulating practices, which provide individuals with ways of understanding themselves, changing themselves and taking action to change others and their environments in the name of improved health. The idea is developed from Foucault's (1984) concept of biopower, the governance and regulation of individuals and populations through practices associated with the body. Biopedagogies occur at multiple 'pedagogical sites' - that is, sites that have the power to teach, to engage 'learners' in making sense of their worlds and their selves and thereby influence how they act. These sites are everywhere around us, in schools, on the web, on television, radio and film, and, for the purpose of this paper, SDP programs.

In the context of a neoliberal performative culture (Rich \& Evans, 2009), we would argue that for SDP interventions, like other programs targeting young people (Powell, 2014), a key component is directed at shaping 'good' bio-citizens (Halse, 2009) who have the knowledge and the desire to make decisions that will enhance their health. As is the case with other SDP elements, the emphasis is on individual responsibility for change rather than addressing structural disadvantage or cultural diversity (e.g., see Hayhurst, 2013). In the two cases described in this paper, these biopedagogical elements seep into each SDP program in various ways, which we discuss below, when it comes to preparing young people for future success or in discussions about health.

\section{Indigenous Peoples, SDP, and Biopedadogies}

Eurocentric approaches to shaping 'good' Indigenous bio-citizens throughout the world, and the roles that sport has played in this colonial project, have received a great deal of scholarly attention including in the SDP literature. For instance, Forsyth and Wamsley (2006) outline how 'government administrations in Canada implemented strict policies and programs [including those pertaining to 
sport] designed to bring indigenous beliefs and customs in line with mainstream values and practices’ (p. 296). Certainly, colonialism produced ideas about Indigenous peoples being inferior, lazy, worthless, unintelligent, and dirty (Adams, 1999). Such colonial discourses continue to impact Indigenous peoples today since colonial domination is still rearticulated and/or is created in new ways (neo-colonialism) (McEwan, 2009), including - we would argue - through some SDP programs. Nicholls and Giles (2011) argue that SDP programs are often based on Eurocentric beliefs and thus often marginalize and suppress participants’ knowledges. Nevertheless, the role that participants’ knowledges - and particularly Indigenous knowledges and pedagogies - play, or could play, in SDP programs has received scant attention. It is for that reason that we conducted our research with two SDP organizations that focus on Indigenous young peoples.

\section{Situating the Research}

The research was conducted with two organizations that use SDP with Indigenous young women: the Vancouver Aboriginal Friendship Centre Society (VAFCS), located in Vancouver, Canada, and Role Models and Leaders Australia (RMLA), located in Perth, Australia.

VAFCS

VAFCS is a non-governmental organization that is situated on the borders of the Downtown Eastside of Vancouver. While it provides services to Indigenous and non-Indigenous community members in a variety of areas, including human rights, health, education and culture, in this paper, we focus on its recreation program, which is mandated to 'provide the urban aboriginal community 
a safe and positive space to participate in sport and recreation activities' (SFU, 2014, para. 4). The recreation program offers a number of initiatives and activities ranging from competitive sport opportunities, particularly basketball and soccer, and cultural, social, and physical activities, which include hip-pop, archery, Pow Wow dancing, and what they refer to as 'West Coast nights' - social evenings where community members get together to enjoy food and participate in cultural activities. $^{1}$

The focus of the research was on participants in VAFCS 'Because We Are Girls Group,' a program offering a female-only space to engage young Indigenous women and girls in VAFCS' activities, especially those offered by the recreation department. The participants take ownership over the program by dictating its direction and activities, which includes sports, recreation, outings, and fundraisers. While our research participants were mostly drawn from this group, we also included young women who participated in other programs within the Centre, such as soccer and basketball.

VAFCS’ recreation programs are supported by a grant from Nike’s N7 Fund. Started by Sam McCracken in 1997 - a Nike executive from the Fort Peck Sioux Tribe - the N7 fund supports Indigenous youth sport programs in Canada and the US, with the goal of selling Nike products at a discounted price directly to Indigenous communities to 'support health promotion and disease prevention programs' (N7 Fund, 2015). In addition to receiving funding, Indigenous groups are given Nike N7 apparel to sell at a discounted price.

RMLA 
Unlike VAFCS, RMLA is a 'private-sector led’ NGO, which operates the Girls Academy program in high schools in across Western Australia, the Northern Territories, and New South Wales (RMLA, 2015). Two of its primary corporate sponsors include Nestlé and Barrick Gold Corporation. The Girls Academy program focuses on Indigenous young girls and women between the ages of 12-18 who 'experience poverty, sickness, misfortune or disconnectedness from their community' (RMLA, 2015, para. 5). Based on the belief that Indigenous young women's needs are often not met, RMLA's main goal is to create a supportive environment and programs to help them realize their full potential (RMLA, 2015).

Our research was conducted at the Girls Academy program in Perth, Australia, which is situated within Clontarf Aboriginal College. Many of the students at the College are boarders who hail from rural areas in Western Australia and the Northern Territory. Like VAFCS, the Girls Academy program focuses mostly on basketball, though it also includes other activities such as fitness programs, cultural excursions, and sporting carnivals.

\section{Methodology: Transnational Postcolonial Feminist Participatory Action Research (TPFPAR)}

This study used a transnational approach to postcolonial feminist participatory action research (TPFPAR). This approach is informed by other T/PFPAR scholars in this area, particularly those working with Indigenous youth and young people from the global South, such as Fine et al. (2008), Lykes \& Sibley (2013) and Koirala-Azad (2009). In brief, the participatory element in action research invokes agency and the active role that traditionally marginalized groups (e.g., Indigenous young women) can play in contributing to the discourses and practices of development (McEwan, 
2009). In essence, PAR practices invert 'who constructs research questions, designs, methods, interpretations, and products, as well as who engages in surveillance' (Fine et al., 2008, p. 161).

In order to account for the multiple social and power relations embedded in global SDP work, while also attending to its increasing focus on 'the local', we see great value in the work of transnational PAR activist scholars such as Fine et al. (2008), who take up research 'with youth in a place [and] across places [...] in order to ...trace global [tracks] of domination and resistance' (Fine et al., 2008, p. 158, italics in original). The argument to be made here is that participatory action work need not be limited by national boundaries, 'the local' or by physical borders of any sort, but rather, can extend or operate across local and national boundaries, and in a variety of contexts (Koirala-Azad, 2009).

We further contend that when transnational PAR is linked to transnational postcolonial feminist approaches (TPFPAR), important collaborations are created that engage academics in more transformative, socially revived research that connects to the diversity and lived experiences of disadvantaged communities (Hayhurst et al., 2015; Frisby, Maguire \& Reid, 2009).

\section{Research Team}

All three authors are white women of Anglo-Irish/Scottish/Welsh ancestry. Hayhurst has conducted research on SDP with various stakeholders - especially young women, primarily in the global South. Giles has conducted research with a variety of organizations that provide sport and recreation programming for Aboriginal youth development in Canada. Wright's contribution to the research described in this paper is derived from her use of the concept of biopedagogies in analyses of young people's responses to health and physical activity.

\section{Ethical considerations and data generation}


Following ethical approval from the Universities of $\mathrm{X}$ and $\mathrm{Y}$ and the relevant Indigenous groups, research agreements were developed and signed by organizations in each country. Throughout the research, we attempted to adhere to the principles of OCAP (Ownership, Control, Access and Possession) (see Lavallée \& Howard, 2011). For example, following ethical approval from the University of $\mathrm{X}$, an advisory council was formed with community members that were mutually agreed upon by VAFCS. This advisory council was crucial for periodically reviewing research processes (e.g., identifying appropriate cultural protocols for engaging with urban Indigenous young people). Similar measures were used to ensure the research with RMLA was conducted in an ethical and responsible manner that resonated with Indigenous knowledge.

Field visits to communities took place in July and October 2012 (Vancouver, Canada) and in May 2013 (Perth, Australia). Hayhurst was fully immersed in VAFCS activities throughout this research, participating in a wide array of activities including volunteering during family and nutrition and cooking nights, and attending the 'Because We Are Girls' youth group meetings. In Australia, Hayhurst spent time at the Girls Academy in their Perth office, and participating in and observing training practices for the girls’ basketball team.

For the broader project of which this article is a part, Hayhurst also conducted semistructured, in-depth interviews with employees from corporate sponsors of both programs, and relevant staff and young women participants in the RMLA and VAFCS programs (for more details see Hayhurst et al., 2015; Hayhurst, Giles \& Wright, 2015). The focus of this article is on the interviews with the program staff and the young women in each site. All participants' names have been replaced with pseudonyms to support anonymity. In Canada, three of the eight staff interviewed identified as Indigenous, and two as non-Indigenous; and in Australia, one of the three staff interviewed identified as Indigenous, with two as non-Indigenous. Of the 20 Indigenous young 
women who participated in the study, eleven, with an age range from 13 to 30 years, were from VAFCS and nine, with an age range from 15 to 17 years, from RMLA.

\section{Photovoice}

Photovoice involves providing each participant with a camera and taking photos, and is a recognized PAR method that is particularly beneficial when working with youth and social justicefocused research (Wang \& Redwood-Jones, 2001). Photovoice activities were used with the Indigenous young women participants to obtain their perspectives on their SDP program. In the case of RMLA, only one young woman chose to participate in photovoice activities, whereas eleven chose photovoice at VAFCS. In addition, VAFCS participants created a collage poster and Power Point presentation to showcase their photos to interested community members - an important piece of knowledge translation and direct result of using a PAR approach (also see Hayhurst et al., 2015).

\section{Sharing Circles}

Sharing circles have been used in previous research with Indigenous communities, are meant to be caring, respectful and compassionate, and are valuable for sharing all aspects of the individual, heart, mind, body, and spirit (Lavallée 2009). These are usually led by a mutually agreed upon facilitator, and are used to provide an opportunity for the young women to share their photos and perspectives on the program with other SDP participants.

In the case of VAFCS, a recreation staff member was selected to conduct the sharing circles following the interviews conducted by Hayhurst. It was felt that her previous experiences 
collaborating with the young women through the Because We're Girls group made her the best person to facilitate the circle. A total of seven young women participated in the sharing circle. Four young women took part in the sharing circle with RMLA participants, and one young woman shared her photos. Hayhurst led this circle due to time constraints and the lack of availability of RMLA staff members. Despite the lower participation rate, an insightful conversation about corporate involvement in RMLA programming was stimulated by this young woman's photos and led to a fruitful discussion.

\section{Data Analysis}

Interviews and photos were analyzed using QSR Nvivo 10, a qualitative software analysis program used to manage data for analysis by researchers. Aspects of thematic analysis (Braun and Clarke, 2006) were used to identify emerging themes from the transcripts of the interviews conducted with the staff members and the young women. The themes were then circulated with each group for verification. These conversations provided a basis through which to inform our analysis process with Nvivo, which was used to identify codes and create themes (a total of 41 themes were developed). Comparative themes were then produced in order to identify common topics and stories across interviewees. For example, similar 'nodes’ (thematic labels created using Nvivo) for young women in each country included "barriers to participation in SGD - poverty”.

Using QSR Nvivo - or any qualitative software program, for that matter - prioritizes Western forms of knowledge production and places the researcher, who typically has access to the software, in a position to make decisions without community members' input. Ultimately, this method of analysis can exacerbate unequal power relations in the research process, and as such, does not correspond to PAR 
approaches (Lavallée 2009). However, due to time and financial constraints, it was difficult to transcribe, code, and categorize the large amounts of narrative from the interviews with the involvement of all research participants. As Reid (2004) notes, it is difficult to make all stages of PAR process participatory; we feel that this is especially in using a transnational PAR approach due to the size, scope and scale of the research.

Our results showed that program staff and the Indigenous young girls and women interviewed saw participation in VACFS and RMLA as a way to learn a number of things: citizenship, self-care, and healthy living; hygiene and health; self-reliance and fundraising; and how to prepare for 'success,' especially through future employment in mainstream organizations and industries. We argue that the purpose of these programs - as they navigated the complex forces of competitive capitalism - was essentially biopedagogical, aiming to develop attributes that encourage Indigenous female bodies to more closely conform with neoliberal values of responsibility - for their health and future lives in an Eurocentric world.

\section{Learning Citizenship, Self-Care and 'Healthy Living' through SDP}

Both programs emphasized the importance of Indigenous young women learning healthy living and self-care strategies - not only to perform well on the basketball court, but also to be healthy citizens. Young women from VAFCS and RMLA discussed how they learned how to 'eat healthy', augment their physical fitness and improve their confidence and self-esteem through their participation in the each respective program. These characteristics were framed positively by the young women and staff as important qualities that were necessary in order for them to navigate daily life in challenging 
urban environments, and were also critical for demonstrating their efforts to be 'good citizens' and role models in their communities.

\section{VAFCS: 'Staying out of trouble' through healthy living}

Akala and Barina (young Indigenous women) pointed to the ways in which the VAFCS program taught them how to 'stay out of trouble' and to avoid 'stereotypical' Aboriginal activities. As Akala commented:

For me, I notice that it [the program] keeps me out of trouble. Like, I won't be doing stereotypical Native things that people think we do. It shows that not everyone goes out and drinks all the time. It shows that I am involved with my community and that I'm here and that I want to be- - I want the younger kids that come here to look up to someone that doesn’t do bad stuff and knows that there's still good people.

Like Akala, Cheera felt that - through the recreation program at VAFCS - she was able to build selfesteem and challenge the perceived stereotypes about Indigenous young women in her community: It's kind of like exactly how it makes me in general, and all the other girls, how they feel when they play basketball. It's the one place where you feel welcome and don't have to worry about what anyone else thinks. Because it does gain you self-esteem...Outside of this community what people think of stereotypes as Aboriginals, dropping out of school and all that. It's ridiculous...Because we're all human.

According to these young women and several others, by not staying at home, they were choosing to be active community members interested in self-improvement and connecting with like-minded people that might offer social support. 
For many of these young women, being involved in VAFCS recreation activities was also about trying to better understand who they were, and hoping to further learn about their cultural roots. As Leura suggested, she was able to do this by attending the weekly powwows that VAFCS offered: We went to those powwows. My kids, they don't have a lot of their cultural influence, mostly because I grew up in the city and I don’t have a lot of it myself. My second oldest son is, like, 'Mom, what band am I from? Like, what nation am I?’ And I told him. He’s like, 'Is there an easier way to say that?' [laughs]...And he’s, like, 'How come we don’t do anything?' And I said, 'Well, there's not a lot in the city.'

At the same time, the expectation (from staff and participants) was that the recreation program would not only contribute to learning about their culture, but would be made more relevant to them by explicitly engaging and connecting traditional Indigenous practices with healthy eating strategies, nutrition, and physical fitness. For example, Ariel, a VAFCS staff member, noted how the recreation curriculum was to be aligned with the medicine wheel to ensure a holistic approach to the participants' development:

Everyone’s learning about preparing food and they're learning about healthy eating and that's just kind of a common for our program ...It's not about results as much as it’s about just being a well-rounded individual. And that's the Aboriginal...you know the medicine wheel circle of life? Like all aspects need to be accounted or need to be attended to in order to be successful. Healthy eating was a central theme that emerged from the interviews, with half of the young women interviewed discussing the importance of avoiding sugary drinks, and two suggesting that 'juicing' was an important healthy alternative, albeit an expensive one. This was best captured through Binda's photo of wheatgrass below (see Figure 1) where she noted that the young women needed to learn more about how to eat healthy on a budget.

[Insert Figure 1 about here. All rights reserved.] 
RMLA: Becoming self-regulating, successful, healthy citizens

RMLA also had an emphasis on educating the participants about health and wellbeing - through learning about and involving the participants in 'active living' - and through their training for basketball and teachings about hygiene, which were intended to prepare them for success in school and beyond. According to staff members, there were a number of requests from the school where the RMLA program was based to teach these young women about 'hygiene and overall appearance.' In a comment that reflected the common trope of comparing the urban girls (i.e., from Perth) to the girls from the more remote communities, Ashley, a RMLA staff member, explained the challenges involved in her work, as she navigated pressures from staff at the girls' school who felt that it was the young women from remote communities who needed to learn about 'personal hygiene':

It can be insulting to focus on that [personal hygience] with a girl who lives in Perth with her family and is perfectly well maintained and understands personal hygiene, but then you've got a [young woman] who comes from a really remote community who showering everyday that's just not part of their upbringing. And you're trying to teach them that as a group, and you don't want to single anyone out, and then you're going, 'I don't want to be insulting either'. Like, this is kind of general knowledge to some of the other girls. So I find that a really difficult topic to address.

Though none of the young women interviewed referred to the effects of this knowledge pertaining to 'personal hygiene', many interviewees noted the inherent challenges involved in learning Western ideals that emphasized being active, healthy and knowing how to take care of oneself. They often compared their 'new lives' in Perth to their life at home, where they were often part of communities where Indigenous youth engaged in activities such as smoking, drugs and alcohol consumption that RMLA's curriculum emphasized as harmful and in need of reforming. The tension between RMLA's 
'grooming and deportment' curriculum and the realities of the lives back home often resulted in challenges to their sense of identity, as they tried to reconcile the structural realities of their home communities with the key pedagogical mandates of the program. As Leumeah, a RMLA participant, lamented:

Most of the girls there [in her home community back home] like, there are drugs there. Like, most of the girls, they get into that sort of stuff...I tried it. I didn’t like it. And then, it was hard, because when I went back home [from Perth], I started smoking again. I’m trying to stop...It’s pretty hard back at home. There’s not really more opportunities there. It’s best to get away.

From the perspective of young women in the program, participating in the basketball program allowed them to improve their physical fitness, become exposed to new places and experiences, build strong networks of support through friendships, and distract themselves from missing 'home life'. Most of young women interviewed (six out of eight) felt the program was beneficial because it kept them 'busy' and gave them something 'to do'. That is, in a similar vein to VAFCS participants, the program seemed instrumental for keeping them active and 'out of trouble'. For example, according to Yindi, the program was crucial for alleviating boredom: 'The program keeps you active. And yeah, they get you going. If you don't have anything to do, they'll give you something to do...It's better than just being at home, really.'

Thus, in biopedagogical terms, both programs were engaged in practices associated with health and well-being and therefore designed to develop the attributes that would assist the participants in becoming healthy self-regulating citizens. We contend that attempting to 'shape' participants in this way was a result of the broader neoliberal contexts that influenced the program mandates. This is not to say that these young women passively accepted these mandates without resistance or agency. We further expand on possibilities for resistance and de-centering the seemingly biopedagogical approach to SDP that target Indigenous young women in the discussion section. 


\title{
Learning how to survive and thrive in the neoliberal era
}

\author{
VAFCS: Self-reliance and fundraising through SDP
}

VAFCS's recreation program was consistently in need of funding and lacked the security of long-term sponsorship from government and its key corporate sponsor (Nike N7). As a result, in the interviews and through the photovoice activities, the importance of the young women learning to be (financially) self-reliant - and to fundraise in order to sustain their participation in the program - was consistently highlighted. Brett, a VAFCS staff member, pointed to what he felt was the federal government's ultimate hypocrisy in cutting funding to the program: 'When the government makes apologies for residential schools and then they cut programming for Aboriginal youth, how then do you expect the community to move forward and to heal and to be healthy?' Four out of the five VAFCS staff interviewed noted how it was imperative for the youth to learn fundraising skills, identifying it as an important life skill:

It's an opportunity to have the kids doing fundraising...it’s an opportunity for them to learn those skills. So they've done things like selling food at west coast nights. During our summer day camp we’ve done car washes and stuff like that. And for the most part kids love it... They like knowing that their efforts are going to raise the revenue that is then going to help pay for some other activities for them to do. It gives them responsibility. It helps them develop those skills and, you know, if you can develop the leaders to kind of take responsibility for organizing those activities they generally work well. But it's also just the small drop in the bucket of what's necessary to run programs (Toby, RMLA staff member). 
Indeed, the young women noted how this pressure to fundraise in innovative and competitive ways was mobilized, and taken up, through various strategies that were ultimately their responsibility. That is, it was clear that developing self-reliance was seen as imperative for the survival of the program, but also - as noted by Toby in the quote above - for the success of the young women outside of the program.

These ideas are clearly evident in the following dialogue between two of the participants:

Coorah: If there wasn’t basketball, there was fundraising for basketball.

Akala: We were told that there was no money and we needed I think roughly ten thousand dollars.

Lyndsay: So what were some of the things you did to fundraise?

Coorah: Bake sales, raffles, that's pretty much it I think. Like, a lot of bake sales... And we'd have, like, 50 cupcakes and 100 cookies to sell. That's all we would have, and no one would really want to buy that. So we have to be creative.

The extent to which a lack of funds permeated the young women's experience was also evident in the need for additional funds for proper footwear. Many of the young women, such as Binda, took photos of their shoes to demonstrate how they needed to raise funds to obtain proper footwear for sport participation (see Figure 2 below). Although Nike N7 sponsored the recreation program at the time, and shoes were being provided at what Nike deemed to be an affordable rate for the young Indigenous women, most of the interviewees suggested that the N7 shoes were too expensive and out of reach.

[Insert Figure 2 about here. All rights reserved.]

RMLA: Preparing Indigenous young women for 'success' through corporate-funded SDP

As we have discussed in our previous work (Hayhurst, Giles \& Wright, 2015), the RMLA program had deep connections with the private sector. Indeed, on its website, RMLA is described as a 'private-sector 
led' non-profit NGO. With major corporate sponsors such as Barrick and Nestlé, RMLA was focused on ensuring the young women participating in the Girls Academies across Australia were able to navigate the complexities of competitive capitalism through specific curriculum that, for example, involved training in marketing, human resource management and/or public relations in Nestlé's head office in Sydney.

The value of what we are referring to as 'key employability skills' was frequently referenced by many of the young women in their interviews. These proficiencies were perceived as crucial to their survival and success, especially as they resided away from their home communities, where few employment opportunities were available. At the same time, skills such as learning English, for instance, instantly separated these young women from others in their home communities. While such skills opened up avenues for postsecondary education and were valuable when interviewing for employment opportunities, honing such skills also created potentially challenging scenarios, whereby the young women felt they were navigating, or caught in-between, 'two worlds'. This is evident in the following interview exchange between Lyndsay and Nioka:

Nioka: When I was growing up, English wasn't my first language.

Lyndsay: What was your first language?

Nioka: Arrernte. So, yeah, my mom put me in school and I was just getting to learn English. And then like mom said to me like, you know, it was hard growing up because my cousins who, my other cousins, who didn’t speak the language I spoke...I used to speak the language to them and they didn't understand what I was saying... And then yeah, as I was growing up I started, you know, seeing the difference and living both worlds, like the Aboriginal, the black world and like the white world.

Indeed, much of RMLA's curriculum seemed to be focused on assisting these Indigenous young women in navigating the 'white world', not only by learning and sharpening their language (English) 
skills, but also by becoming financially literate and by acquiring workplace proficiencies that would facilitate future employment, alongside their participation in basketball. For example, as Tahlee explains in the following quote, the training provided by Nestlé involved the girls watching videos on 'how to get a job’:

We watch a video and they'll just show you how to get a job and that. And how you get your tax and all that, there. And your payments. And how to get your money and get it in a bank account and that....it's helped me to try and get a job, like in the future.

All of the young women explained the importance of corporate involvement in the RMLA program: it was not simply about learning employment skills, providing workplace opportunities and how to navigate the job market, but Nestlé also financially supported some of the young women's education. In a similar vein to the young women participating in the VAFCS' program, interviewees highlighted their pride in being associated with influential, well-recognized brands. As Nioka explained in describing why she took the photo in Figure 3, 'it's good to have companies to help out because I reckon without them this program would probably struggle... So, it's a really great idea that they... like helping sponsoring and all that.'

[Insert Figure 3 about here. All rights reserved.]

\section{Discussion}

Our findings offer a potentially fruitful comparative foundation from which to consider the key tensions and fluctuating roles that neoliberalism, education and (bio)pedagogies play in two distinct, yet analogous, SDP programs that target Indigenous young women in urban metropolises in two settler colonies. Our comparison is challenging in that we do not wish to ignore critical differences or disregard the local cultural particularities of each participant and program; that is, we are concerned 
about generalizing from the 'local' to 'global' (Fine et al., 2008). And yet, our aim in using a transnational PFPAR approach is to better understand how these communities might learn from each other, and develop possible solidarities through their common struggles as NGO staff members and Indigenous young women to possibly form a counter-hegemonic buffer against global capitalism and neoliberal biopedagogies.

In both programs, activities were designed to equip the Indigenous girls and young women with those individual attributes that would enhance their chances of future success in arenas valued by neoliberal capitalism: Eurocentric employment, post-secondary education, and healthy active living. These forms of 'success' clearly fall within neoliberal logic where the focus is on the individual being able to provide for oneself, particularly in the context of the retreating welfare state in both Canada and Australia. What seems to be missing from this logic, however, is the consideration that these young women are participating in these arenas as Indigenous peoples. For these young women, success will not merely come with their hard work; rather, systemic gender and race-based discrimination and the chronic under funding of almost all of the determinants of health for Indigenous peoples in Canada and Australia provide powerful evidence that their future participation in Eurocentric institutions is likely to be less than successful if broader societal change does not occur at the same time.

And yet, while it would be easy to see these SDP programs as neocolonial tools, we advise caution in such interpretations. As Lavallée (2008) and Wilson, W. (2005) remind us, physical activity and health promotion programs can be used by Indigenous peoples to decolonize their lives in order to achieve their own 'good.' Importantly, however, the design and delivery of such programs must be built on a foundation of Indigenous knowledge, beliefs, and practices. The young women in the VAFCS and RMLA programs all argued that their participation in the SDP programs would help them change racist and sexist stereotypes about their communities, usually through changes in the ways they 
conducted themselves, and thereby challenged negative stereotypes. Thus, it is possible that these programs, despite their predominant use of neoliberal logic, may help prepare the participants to more successfully engage in Eurocentric institutions and through this assist the participants in contributing to social change. A longitudinal project would be needed to explore such possibilities. Our study suggests however that if the young women in the program are to celebrate their Indigenous identities and work from that basis for social change, there needs to be fundamental shifts to program structure and content that would foreground Indigenous peoples and their knowledge in the development and implementation of SDP programs. Changes that are made all the more challenging due to the reliance on corporate sponsorships.

It was clear that both initiatives experienced intense pressures related to funding, which facilitated corporate intervention in these programs. At the same time, the participants in this study did not necessarily want to prevent these corporate actors from permeating their space, displaying corporate logos or selling products to their communities, friends and family. That is, these programs particularly through their affiliations with corporate sponsors, were perceived to provide access to the 'goods' of the societies in which the young women lived. As Grande (2008, p. 235) argues of Indigenous scholars who live in a 'Whitestream world', they have 'no choice but to negotiate the forces of colonialism, to learn, understand and converse in the grammar of empire as well as develop the skills to contest it'. Similarly, we suggest that the SDP programs such as those described in this paper and their corporate sponsors do arm these young women with tools to better participate in the 'Whitestream worlds’ of Canada and Australia, but, we argue, a greater investment in Indigenous (bio)pedagogies could address the conflicts some of the young women described in their relationships with their home communities and better develop the skills to contest the 'Whitestream worlds' which they live. 


\section{Conclusions, Reflections and Suggestions: The responsibility to carry hope?}

To conclude, we ask how through the leadership of Indigenous peoples within SDP, programs could be fundamentally shifted away from focusing on building citizens who are primed for successful participation in competitive capitalism to equipping young Indigenous peoples with the skills identified within their own communities as being important to successfully navigate and disrupt broader systemic and structural inequalities, such as poverty, racism, colonialism and sexism.

As Fine et al. (2008, p. 166), referring to their transnational PAR work with youth across the globe, argue, 'These young people, in their lives and their work, carry the ashes of global capitalism, racism, sexism, and colonialism, and now are imbued with the responsibility to carry hope'. In many ways, this quote from Fine et al. resonates with the common theme across the research sites: that Indigenous young women shoulder a great deal of 'responsibility to carry hope' forward for their communities. In the case of the research conducted here, we suggest that this hope is largely ignited through the biopedagogical mandates of these programs that aim to prepare these young women for success - as defined by Eurocentric neoliberal logic.

Importantly, we are cautious not to critique the efforts of the NGOs discussed in this paper for wanting to better prepare, and equip, these young women to learn how successfully participate in competitive capitalism. To clarify, the focus of our critique is on the system(s) within which these programs work - and not the actual programs themselves. We are particularly concerned about the broader social, political, historical and economic systems these programs have to work within and the ways these systems influence their mandates, particularly as they 'teach’ Indigenous young women to be neoliberal citizens. At the same time, we wonder how broader SDP programs that are led by Indigenous peoples might be de-centered to foreground capitalist and neo-colonial relations as a key 
axis of exploitation, so that they can and uphold the 'imperatives of indigenous sovereignty and selfdetermination' (Grande, 2008, p. 238)?

Our goal in this paper was to trace and uncover the biopedagogical tentacles of SDP focused on Indigenous young women. We argue that SDP programs, designed by Indigenous peoples, and which prioritize the 'standpoint of colonized peoples on a geopolitics built on hierarchies, hegemony, and privilege in the larger effort to transform an unjust world' (Kincheloe \& Steinberg, 2008, p. 135) could shake the very essence of SDPs' pedagogical foundation. Indeed, several authors have argued that Indigenous physical practices and other health-promoting practices can play important roles in broader decolonization efforts. For example, Lavallée (2008) argues that physical activity can help First Nations women learn about their cultural identities, challenge low self-esteem, and foster well-being. Importantly, though, the participants in her study commented on the importance of the physical activity program being conducted in a culturally appropriate location (the Native Canadian Centre of Toronto) and on having an Indigenous instructor who integrated cultural teachings in the physical activity program. If such practices were the basis for SDP, the programs need not be only about reinscribing colonial tropes, but can also play a role in rejecting them.

To conclude, we ask how might SDP interventions address the core systemic exploitation systems endured by Indigenous peoples? Is this too much to ask of a SDP pedagogy? While we hope the answer is a resounding 'no' - we contend that the time is certainly ripe for future transnational postcolonial feminist participatory action research in this area.

\section{Acknowledgements}

The authors acknowledge the support of the Social Sciences and Humanities Research Council of Canada (Postdoctoral Fellowship), Sport Participation Research Initiative and an Endeavour Research Fellowship. We would also like to extend our sincere appreciation and gratitude to the young women 
and staff at the Vancouver Aboriginal Friendship Centre Society and Role Models and Leaders Australia who shared their stories and viewpoints for this research. We hope to have done justice to your experiences through writing this paper. We also wish to thank the editors and anonymous reviewers at Sport, Education and Society for their comments on earlier versions of this manuscript. 


\section{References}

Adams, H. (1999). Tortured people: The politics of colonization. Penticton, Canada: Theytus Books. Andrews, D. L. \& Silk, M. L. (2012). Sport and the neoliberal conjuncture: Complicating the consensus. In D. L. Andrews \& M. Silk (Eds.), Sport and neoliberalism: Politics, consumption and culture (pp. 1-23). Philadelphia, PA: Temple University Press.

Bhanji, Z. (2008). Transnational corporations in education: Filling the governance gap through new social norms and market multilateralism? Globalisation, Societies and Education, 6(1), 55-73. doi:10.1080/14767720701855618.

Braun, V. \& Clarke, V. (2006) Using thematic analysis in psychology. Qualitative Research in Psychology, 3(2), 77-101.

Darnell, S. C. (2012). Sport for development and peace: a critical sociology. London, UK: Bloomsbury.

Evans, J., \& Davies, B. (2015). Physical education, privatisation and social justice. Sport, Education and Society, 20(1), 1-9. doi:10.1080/13573322.2014.942624

Fine, M., Tuck, E., \& Zeller-Berkman, S. (2008). Do you believe in Geneva? Methods and ethics at the global-local nexus. In N. Denzin, Y. Lincoln, \& L. T. Smith (Eds.), Handbook of critical and indigenous methodologies (pp. 157-177). London, UK: Sage.

Forde, S., \& Frisby, W. (2015). Just be empowered: How girls are represented in a sport for development and peace HIV/AIDS prevention manual. Sport in Society: Cultures, Commerce, Media, Politics. Advance online publication. doi:10.1080/17430437.2014.997579 
Forsyth, J., \& Wamsley, K. B. (2006). ‘Native to Native...we'll recapture out spirits’: The World Indigenous Nations Games and North American Indigenous Games as cultural resistance. International Journal of the History of Sport, 23(2), 294-

314. doi:10.1080/09523360500478315

Foucault, M. (1984). The History of Sexuality, Volume I: an introduction, Harmondsworth, Middlesex, England: Peregrine, Penguin Books.

Frisby, W., Maguire, P., \& Reid, C. (2009). The “f” word has everything to do with it: How feminist theories inform action research. Action Research, (7)1, 13-29.

Giles, A. R. (2008). Beyond ‘add women and stir’: Politics, feminist development, and Dene games. Leisure/Loisir, 32(2), 489-512.

Grande, S. (2008). Red pedagogy: The un-methodology. In N. Denzin, Y. Lincoln, \& L. T. Smith (Eds.), Handbook of critical and indigenous methodologies (pp. 233-255). London, UK: Sage. Halse, C. (2009) Bio-citizenship: Virtue discourses and the birth of the bio-citizen. In J. Wright \& V. Harwood (Eds.), Biopolitics and the 'obesity epidemic' (pp.45-59). New York: Routledge. Harvey, D. (2005). A brief history of neoliberalism. Oxford, UK: Oxford University Press.

Harwood, V. (2009). Theorizing biopedagogies. In J. Wright \& V. Harwood (Eds.), Biopolitics and the “obesity epidemic:” Governing bodies (pp. 15-28). London, UK: Routledge.

Hayhurst, L.M.C. (2015). Sport for Development and Peace: A Call for Transnational, Multi-Sited, Postcolonial Feminist Research. Qualitative Research in Sport, Exercise \& Health. doi: 10.1080/2159676X.2015.1056824.

Hayhurst, L.M.C. (2013). Girls as the 'new’ agents of social change? Exploring the 'Girl Effect' through Sport, Gender and Development programs in Uganda. Sociological Research Online (Special Issue: Modern Girlhoods), 18(2). 
Hayhurst, L.M.C. (2011). Corporatising sport, gender and development: Postcolonial IR feminisms, transnational private governance and Global Corporate Social Engagement (GCSE). Third World Quarterly, 32(3), 531-549.

Hayhurst, L.M.C., Giles, A.R., Radforth, W. \& The Vancouver Aboriginal Friendship Centre Society (2015). “I want to come here to prove them wrong”: Using a Postcolonial Feminist Participatory Action Research (PFPAR) approach to studying Sport, Gender and Development programs for urban Indigenous young women. Sport in Society. doi:

10.1080/17430437.2014.997585.

Hayhurst, L.M.C., Giles, A.R. \& Wright, J. (2015). The benefits and challenges of girl-focused Indigenous Sport for Development and Peace programs in Australia and Canada. In L.M.C. Hayhurst, T. Kay \& M. Chawansky (Eds.), Beyond Sport for Development and Peace: Transnational perspectives on theory, policy and practice (pp. 111-127). London: Routledge. Hayhurst, L.M.C. \& Giles, A.R. (2013). Private and moral authority, self-determination, and the ‘domestic transfer objective:’ Foundations for understanding Sport for Development and Peace in Aboriginal communities in Canada. Sociology of Sport Journal, 30, 504-519.

Kidd, B. (2008). A new social movement: Sport for development and peace. Sport in Society, 11(4), 370-380. doi:10.1080/17430430802019268

Kincheloe, J.L. \& Steinberg, S.R. (2008). Indigenous knowledges in education: Complexities, dangers and profound benefits. In N. Denzin, Y. Lincoln, \& L. T. Smith (Eds.), Handbook of critical and indigenous methodologies (pp. 157-177). London, UK: Sage. 
Koirala-Azad, S. (2009). Exploring the intersection of philanthropy, research, and scholarship in a Third World context. Social Justice, 36(4), 84-97. Retrieved from http://www.jstor.org/stable/29768563

Lavallée, L. (2008). Balancing the medicine wheel through physical activity. Journal of Aboriginal Health, 4(1), 64-71. Retrieved from http://www.naho.ca/jah/english/jah04_01/09MedicineWheel_64-71.pdf

Lavallée, L. F. (2009). Practical application of an Indigenous research framework and two qualitative Indigenous research methods: Sharing circles and Anishnaabe symbol-based reflection. International Journal of Qualitative Methods, 8(1), 21-39. Retrieved from http://ejournals.library.ualberta.ca/index.php/IJQM/article/view/943

Lavallée, L. F., \& Howard, H. A. (2011). Urban Aboriginal Diabetes Research Project Report. Toronto, Canada: Anishnawbe Health Toronto.

Lindsey, I., \& Grattan, A. (2012). An 'international movement’? Decentring sport-for-development within Zambian communities. International journal of sport policy and politics, 4(1), 91-110. doi:10.1080/19406940.2011.627360

Lykes, M. B., \& Sibley, E. (2013). Exploring meaning-making with adolescents 'left behind’ by migration. Educational Action Research, 21(4), 565-581. doi:10.1080/0965092.2013.832346

McEwan, C. (2009). Postcolonialism and development. London, UK: Routledge.

McGuire-Adams, T. (2015). Decolonizing bodies: Disabling embodied settler colonialism by building strong bodies. Manuscript submitted for publication.

Mohanty, C. T. (2013). Transnational feminist crossings: On neoliberalism and radical critique. Signs, 38(4), 967-991. Retrieved from http://www.jstor.org/stable/10.1086/669576 
Nicholls, S., Giles, A. R., \& Sethna, C. (2011). Perpetuating the 'lack of evidence’ discourse in sport for development: Privileged voices, unheard stories and subjugated knowledge. International Review for the Sociology of Sport, 46, 249-264.

N7 Fund. (2015). N7 fund. Retrieved from http://n7fund.com

Powell, D. (2014). Childhood obesity, corporate philanthropy and the creeping privatisation of health education. Critical Public Health, 24(2), 226-238. doi:10.1080/09581596.2013.846465

Reid, C. (2004). Advancing women's social justice agendas: A feminist action research framework. International Journal of Qualitative Methods, 3(3), 1-13. Retrieved from https://www.ualberta.ca/ iiqm/backissues/3_3/pdf/reid.pdf

Rich, E. \& Evans, J. (2009). Performative health in schools: Welfare policy, neoliberalism and social regulation. In J. Wright \& V. Harwood (Eds.), Biopolitics and the 'obesity epidemic' (pp.157171). New York: Routledge.

Role Models and Leaders Australia (RMLA). (2015). Girls Academies. Retrieved from http://www.girlsacademy.com.au

Rossi, T., \& Rynne, S. (2014). Sport development programs for Indigenous Australians: Innovation, inclusion and development, or a product of 'white guilt'? Sport in Society, 17(8), 1030-1045. doi:10.1080/1740437.2013.838355

Truth and Reconciliation Commission of Canada. (2015). Honouring the truth, reconciling for the future: Summary of the final report of the Truth and Reconciliation Commission of Canada. Retrieved from http://www.trc.ca/websites/trcinstitution/File/2015/Findings/Exec_Summary_2015_05_31_web -o.pdf 
Vancouver Aboriginal Friendship Centre Society (VAFCS). (2015). Cultural nights. Retrieved from www.vafcs.org/events/culturalnights

Wang, C., \& Redwood-Jones, Y. (2001). Photovoice ethics: perspectives from flint photovoice. Health. Education and Behavior, 28(5), 560- 572.

Wilson, B. (2012). Sport and peace: A sociological perspective. Toronto, Canada: Oxford University Press.

Wilson, W. A. (2005). Decolonizing Indigenous diets. In W. A. Wilson \& M. Y. Bird (Eds.), For Indigenous eyes only: A decolonization handbook (pp. 67-86). Sante Fe, NM: School of American Research Press.

Wright, J. (2014). Beyond body facism: the place for health education. In K. Fitzpatrick \& R. Tinning (Eds.), Health Education: Critical Perspectives (pp. 233-248). Abingdon, United Kingdom: Routledge.

Wright, J. (2009). Biopower, Biopedagogies and the obesity epidemic. In J. Wright \& V. Harwood (Eds.), Biopolitics and the 'Obesity Epidemic': governing bodies (pp. 1-14). New York: Routledge.

\section{Notes}

${ }^{1}$ Pow Wow is a cultural tradition described on the VAFCS website as when, "individuals, families and community come together to witness and participate in the singing and drumming of the Pow Wow tradition. The VAFCS appreciates hearing the songs and the spirit of the drums which communicates their ancestral values, cultural integrity, solidarity and personal relationships for future generations" (VAFCS, 2015). 